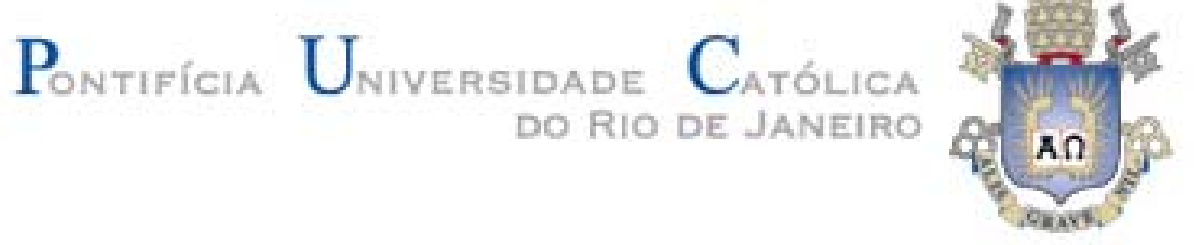

Fernanda Farah de Abreu Zorman

Influência do BNDES na Governança das Empresas Brasileiras Listadas

Dissertação de Mestrado

Dissertação apresentada ao Programa de Pósgraduação em Administração de Empresas da PUCRio como requisito parcial para obtenção do titulo de Mestre em Administração de Empresas.

Orientador: Prof. André Luiz Carvalhal da Silva 
Fernanda Farah de Abreu Zorman

\title{
Influência do BNDES na Governança das Empresas
}

Brasileiras Listadas

\begin{abstract}
Dissertação apresentada como requisito parcial para obtenção do grau de Mestre pelo Programa de Pósgraduação em Administração de Empresas da PUC-Rio. Aprovada pela Comissão Examinadora abaixo assinada.
\end{abstract}

Prof. Andre Luiz Carvalhal da Silva Orientador Departamento de Administração - PUC-Rio

Prof. Luiz Felipe Jacques da Motta Departamento de Administração - PUC-Rio

Prof. Ricardo Pereira Câmara Leal

UFRJ

Prof ${ }^{a}$. Mônica Herz

Vice-Decana de Pós-Graduação do CCS

Rio de Janeiro, 4 de abril de 2012 
Todos os direitos reservados. É proibida a reprodução total ou parcial do trabalho sem autorização da universidade, da autora e do orientador.

\section{Fernanda Farah de Abreu Zorman}

Graduou-se em Administração pela Universidade Federal do Rio de Janeiro (UFRJ) em 2002. Atua como gerente no Banco Nacional de Desenvolvimento Econômico e Social (BNDES).

Ficha Catalográfica

Zorman, Fernanda Farah de Abreu

Influência do BNDES na governança das empresas brasileiras listadas / Fernanda Farah de Abreu Zorman ; orientador: André Luiz Carvalhal da Silva. - 2012.

41 f. : il. (color.) ; $30 \mathrm{~cm}$

Dissertação (mestrado)-Pontifícia Universidade Católica do Rio de Janeiro, Departamento de Administração, 2012.

Inclui bibliografia

1. Administração - Teses. 2. Governança corporativa. 3. Investidores institucionais. 4. BNDES. I. Silva, André Luiz Carvalhal da. II. Pontifícia Universidade Católica do Rio de Janeiro. Departamento de Administração. III. Título. 


\section{Agradecimentos}

Ao Andre Zorman, meu amor de toda a vida.

Aos meus filhos, João Pedro e Luis Felipe, pela sua existência e doçura que tornam a vida completa e colorida, e que, aos meus olhos, representam o meu maior presente de Deus.

A minha família, pela compreensão. À minha mãe Lygia e ao meu pai Claudio, que me ensinaram as coisas mais importantes da vida. A minhas irmãs Bianca e Mariana, pelo autêntico companheirismo.

A minhas avós e à Ude, que me apresentaram à palavra “determinação”.

Ao Sr. Rogério Vieira, que veio somar alegrias e bons momentos à nossa família.

Aos meus amigos, sempre presentes em todos os momentos. Os íntimos acompanharam toda essa empreitada e sabem quanto foram importantes ao longo desse caminho.

Ao Sr. Jorge Eduardo Moraes e ao Sr. Fabio Sotelino da Rocha, pelo apoio na realização desse curso.

À Sra. Luciane Gorgulho e Sr. Maurício Neves, pelo apoio no período de conclusão desse trabalho. Ao Sr. Julio Ramundo pela motivação e reconhecimento.

Ao meu orientador André Carvalhal e aos professores do IAG PUC-RIO, por todos os conhecimentos compartilhados.

À equipe do IAG, pela convivência e pelo suporte oferecido durante o curso. 


\section{Resumo}

Zorman, Fernanda Farah de Abreu; Silva, André Luiz Carvalhal da. Influência do BNDES na Governança das Empresas Brasileiras

Listadas. Rio de Janeiro, 2012. 41p. Dissertação de Mestrado. Departamento de Administração, Pontifícia Universidade Católica do Rio de Janeiro.

O objetivo da pesquisa é verificar a influência do Banco Nacional de Desenvolvimento Econômico e Social (BNDES) na governança das empresas brasileiras listadas na BMF\&BOVESPA. Existem muitos estudos na literatura que analisam o ativismo dos investidores institucionais na melhora da governança das empresas, em geral focados na atuação de fundos de pensão e fundos de private equity e venture capital. São poucos os estudos que analisam a atuação de um banco de desenvolvimento estatal na governança das empresas. No caso brasileiro, esse tema se torna ainda mais importante, uma vez que o BNDES possui a maior carteira de ações no país. Foram analisadas 275 empresas listadas no período de 2002 a 2009, das quais 117 estavam presentes na carteira do BNDES. Foram realizados testes de diferenças e estimados modelos econométricos, controlando por auto-seleção e endogeneidade, para verificar a relação entre a presença do BNDES e a governança das empresas. Os resultados demonstram que as empresas que contam com o BNDES como acionista apresentam melhor governança.

\section{Palavras-chave}

Administração; governança corporativa; investidores institucionais; BNDES. 


\section{Abstract}

Zorman, Fernanda Farah de Abreu; Silva, André Luiz Carvalhal (Advisor). Influence of BNDES in the Governance of Brazilian Listed Companies. Rio de Janeiro, 2012. 41p. MSc. Dissertation - Departamento de Administração, Pontifícia Universidade Católica do Rio de Janeiro.

The objective of this research is to examine the influence of BNDES in the governance of Brazilian companies listed on BM\&FBOVESPA. There are many studies in the literature about the activism of institutional investors to improve corporate governance in general focused on the performance of pension funds, private equity and venture capital funds. There are few studies that analyze the influence of state development banks in corporate governance. In the Brazilian case, this issue becomes even more important, since BNDES has the largest equity portfolio in the country. We analyzed 275 listed companies from 2002 to 2009, of which 117 were present in the portfolio of BNDES. We perform tests of differences and run econometric models controlling for self-selection and endogeneity to investigate the relationship between BNDES and corporate governance. The results show that firms with BNDES as shareholder have better governance.

\section{Keywords}

Business administration; corporate governance; institutional investors; BNDES. 


\section{Sumário}

1. Introdução 9

2. Revisão Bibliográfica 12

2.1. Governança Corporativa e Ativismo dos Investidores
Institucionais

2.2. Governança Corporativa e Investidores Institucionais no Brasil 16

3. O BNDES no Mercado de Capitais Brasileiro 19

4. Dados e Metodologia 22

5. Análise dos Resultados 26

6. Conclusões 35

7. Referências Bibliográficas 37 


\section{Lista de tabelas}

Tabela 1 - Características Econômico-Financeiras das Firmas Classificadas de Acordo com a Presença do BNDES com Acionista

Tabela 2 - Matriz de Correlações

Tabela 3 - Governança Corporativa e BNDES

Tabela 4 - Modelo Probit para BNDES como Acionista

Tabela 5 - Medidas Alternativas de Governança Corporativa e

Presença do BNDES

Tabela 6 - Governança Corporativa e Participação do BNDES no Capital Votante e Total 